\title{
The Reflection of Contemporary Chinese Social Mentality \\ via Internet: A Content Analysis of Comments \\ from the Pray-for-blessings Website
}

\author{
Fuyang Yu \\ Department of Psychology, Qufu Normal University \\ 57 Jing Xuan Rd W., Qufu 273165, Shandong, China \\ E-mail: kevinyu1983@gmail.com \\ Zhaoxu Li (Corresponding author) \\ Department of Psychology, Qufu Normal University \\ 57 Jing Xuan Rd W., Qufu 273165, Shandong, China \\ E-mail: lizhaoxu@china.com \\ Ying Li \\ Department of Psychology, Qufu Normal University \\ Lulu Jiang \\ Department of Psychology, Qufu Normal University \\ Jia Liu \\ Department of Psychology, Qufu Normal University
}

This report was first presented at The CASP Conference to Celebrate the 100th Anniversary of Social Psychology, held in October, 2008, Tianjin, People's Republic of China. It also won the Prize of excellent papers.

\begin{abstract}
This research made a content analysis of comments from a pray-for-blessings website after the 2008 Sichuan Earthquake happened. Contemporary Chinese social mentality is supposed to be reflected by the results. It explores that most netizens wrote the comments in the National Mourning Day. The contents of these comments are divided into 13 species: pray for the disaster areas, pray for China, pray for the rescuers, pray for others, group cohesion, suggestions, love, sympathy, questioning the China Seismological Bureau, appreciation, information of earthquake, schadenfreude, uselessness of praying. Although there was some negative emotion as schadenfreude and some complains appeared, the whole was positive. The source of negative ones may be from high expectation of China Seismological Bureau and dissatisfaction of the society. Theism and antitheism both existed, there was more theism in the pray-for-blessings, however, antitheism was the primary. In all, the whole country is in the social mentality of the all-concerned, comity, love, cooperation, and advocation of science.
\end{abstract}

Keywords: Social mentality, Pray-for-blessings, Content analysis, Internet 


\section{Introduction}

Social mentality is a pervasive and all-encompassing macro-phenomena embedded in the whole society. It is the summation of the emotional tune, social consensus and social values. Social mentality influences social participators' potential contingencies and emotions according to the mechanism of social identification, motivation and emotion, de-individualization. This mechanism relies on the investigation of social popularity, consensus, motivation and confidence towards future to interact the relationship with mainstream ideology (Yang, 2006). China is in the Social Transform Period and keeping a positive social mentality is of great significance. When the society is confronted with an emergency, administration and instruction of social mentality is vital for the government to guide the public. The construction of harmonious society brings a lot of urgent issues in social psychology and personality studies, which calls for Chinanized research (Huang, 2007).

$14: 28,5 / 12 / 2008$ is the moment when the Sichuan Earthquake took place. It shocked every Chinese and would be memorized in the history of China. When all kinds of media reported the situation of the disaster and succor, officers and the rescue forces went to the disaster areas immediately, however, not every warm-blooded Chinese could go to the frontline by himself. With the desire not being satisfied, they begun to feel anxious and stressful, Katz put forward "using and satisfied" theory-audience can control which to choose when they are confronted with the comments. It says that the audience are not passive, which means they can choose media to use according to their own needs and motivation (Fang, 2007). As a result, netizens vented their anxiety and stress through the Internet with various kinds of attitudes to death. When the Pray-for-blessings Website came into being, more and more netizens communicated with each other which plays a very important role in reforming a social support system.

There are usually some people and things that are mysterious and surreal from the folk custom by which people modulate mentality, overcome mental problems, and relieve their worries. This is presented in various kinds of folk cultures (Jing, 2002). From the affair of Chinese Emperor Xuanzong of Tang and his high-ranked imperial concubine Yang Guifei praying to the moon for blessing to the Joss paper, antithetical couplet and candles, the contents of pray-for-blessings are various among Chinese people. Qufu, which is the hometown of Confucius (the greatest educationalist in China) hold several important blessing ceremonies every year, and some of them are held officially, which pray for the prosperity of the nation and some are carried by the folk, which pray for the bright futures of the whole family (especially for offspring). All of these pieces of evidence are proving the fact that praying-for-blessings is essential in Chinese lives. According to the Chinese logic, one should cherish his/her own blessing, and never grudge blessing to others. Many people have posted their comments online for people who were suffering in no more than an hour. Up to the point when the author has finished the article, 2548846 comments were posted and 326 pieces of them were being discussed popularly.

\section{Method}

\subsection{Sampling}

The comments (time, location, and topic) were taken from Tencent Pray-for-blessings website randomly from 15:36 on May 12, 2008 to 00:00 on May 22, 2008. There were 590 pieces of comments after kicking out invalid ones from 630.

\subsection{Design and steps}

The time period of comments were divided into there parts. The first period is from 14:28 of May 12, 2008 to 14:28 of May 15, 2008.which is the Golden Rescue Time. The second period is from "Tou Qi" ("Tou Qi” in Chinese folk custom means festa regarding to the seventh day after a person's death and relatives will hold a memorial ceremony for the person on Tou Qi) to 00:00 of May 19 (Sun, 2000). The third period of time is the national Mourning Day. The concrete time of posted comments were divided into four parts: Early morning (00:00:00 - 06:00:00), morning (06:00:01 12:00:00), afternoon (12:00:01 - 18:00:00), and evening (18:00:01 - 23:59:59).

A single comment can be split into several units representing a complete topic on its own. After the divisions, 1092 items were split from the original comments as the final sample for analysis.

1092 words representing its psychological meanings were extracted from the 1092 items. These were divided into Pray-for-blessings and Non pray-for-blessings elements. Here's an example: "Let's pray for safety and harmony together" as praying element, and to put "I'll adopt a little girl who has lost her parents in order to show my sympathy for those who are in the disaster area" into the Non pray-for-blessings elements. Gather elements with similar contents into the same category.

Classify elements into positive or negative dimensions. Vague items are identified as the uncertain. (Fredrickson, 2001)

Classify elements into theistic or atheistic dimensions. Theism: a combination of soul of humanity and spirit of gods, they both can communicate with each other but they actually have different bodies (Wilber, 1989). For example, "Jesus Christ, would you take back your anger and bless Sichuan", "Hope God will bless Chinese descendents". Vague items are identified as the uncertain.

Statistics is completed by using Microsoft Excel 2003 and SPSS for Windows 13.0. 


\section{Results}

\subsection{Time of comments}

After $\chi^{2}$ test as shown in table 1 , there is significant difference between number of comments in three periods $\left(\chi^{2}(2\right.$, $\left.\mathrm{N}=590)=72.495>\chi^{2} 0.05_{(2)}=5.99, \mathrm{p}<0.05\right)$. There are more netizens posting comments in National Mourning Days while there are more netizens posting comments during nights $\left(\chi^{2}(3, \mathrm{~N}=590)=26.215>\chi^{2} 0.05_{(3)}=7.81, \mathrm{p}<0.05\right)$. (Insert Table 1 here)

\subsection{Categories of Pray-for-blessings elements}

Four categories were extracted from Pray-for-blessings elements as shown in Figure 1: "pray for disaster areas" (75\%), "pray for China" (21\%), "pray for rescuers" $(2 \%)$ and "pray for others" $(2 \%)$. "Pray for disaster areas" took the highest weight, while "pray for rescuers" and "pray for others" took the lowest.(Insert Figure1 here)

\subsection{Categories of Non pray-for-blessings elements}

Nine categories were extracted from Non pray-for-blessings elements as shown in Figure 2. They are listed by weights as follows: "group cohesion" (24\%), "suggestions" (19\%), "love" (17\%), "sympathy" (12\%), "questioning to the China Seismological Bureau" (8\%), "appreciation" (8\%), "information of earthquake" (5\%), "schadenfreude" (4\%), and "useless of praying" (3\%).(Insert Figure2 here)

\subsection{Difference test of elements on emotional dimensions}

As shown in table 3, all of the Pray-for-blessings and Non pray-for-blessings elements are divided by emotional dimensions of positive emotion, negative emotion and uncertain. After crosstab test, there is significant difference between pray-for-blessings elements and Non pray-for-blessings elements on dimensions of positive emotion and negative emotion $\left(\chi^{2}(2, \mathrm{~N}=1092)=359.134>\chi^{2} 0.05_{(3)}=7.81, p<0.05\right)$. There are more positive items in pray-for-blessings elements than those in Non pray-for-blessings elements, and less negative ones. In sum, there are more positive elements than negative ones $\left(\chi^{2}(2, \mathrm{~N}=1092)=1250.423>\chi^{2} 0.05_{(2)}=5.99, p<0.05\right)$. (Insert Table 2 here)

\subsection{Difference test of elements on theistic and atheistic dimensions}

As shown in table 4, all of the Pray-for-blessings and Non pray-for-blessings elements are divided by theistic, atheistic and uncertain dimensions. After crosstab test, there is significant difference between pray-for-blessings elements and Non pray-for-blessings elements on theistic and atheistic dimensions $\left(\chi^{2}(2, \mathrm{~N}=1092)=1290.797>\chi^{2} \quad 0.05_{(2)}=5.99\right.$, $\mathrm{p}<0.05)$. There are more atheistic items in pray-for-blessings elements than those in Non pray-for-blessings elements. Basically, there are more atheistic elements that theistic elements $\left(\chi^{2}(2, \mathrm{~N}=1092)=1290.797>\chi^{2} 0.05_{(2)}=5.99, \mathrm{p}<0.05\right)$. (Insert Table 3 here)

\section{Discussion and Conclusion}

\subsection{Time of pray-for-blessings}

It explores that most netizens wrote the comments in the National Mourning Day. People are so concentrated on the damage and relief work live on TV in the first 72 hours. On "Tou Qi", the number of comments is less than what we expected, which is very different from the custom in our actual life. Also, "Tou Qi" didn't turn up in the comments. Pray-for-blessings via Internet is a new media which makes netizens neglect some fixed custom or norms. In the period of National Mourning Day, people begin to pray-for-blessings for the victims by various ways in response to the calls from various groups. Surprisingly, a lot of people post comments in the early morning, from which we can obviously see that earthquake shock people greatly.

\subsection{Pray-for-blessings are the main contents with earthquake relief the primary task}

In our actual life, the aim of praying is for good fortune, emolument, longevity, wealth and happy events, but in the peculiar period of earthquake, that netizens wrote comments on line to express their attention to people who live in the earthquake area, and also address their viewpoints. By doing this, they can experience their existence and do some contributions to the disaster area, so they gain the delight of being self-actualized (Zhang \& Zou, 2006). Pray-for-blessings elements account for $67 \%$ of all elements, among which pray for disaster areas account for $75 \%$. Since information was transparent and sufficient during that period of time, all the nation formed a social mentality of full attention and overcoming the disaster together by social behaviors like communication and social involvement. This social mentality provides a psychological basis of public participation against the disaster.

In the category of "to pray for disaster areas", "to wish the alive people brave", "to rebuild homestead as soon as possible", "to wish everything be better", "the disaster will be soon gone", "insist" and "to re-collect" were the words which the netizens used frequently. It proves that when the disaster broke out, safety became the first need to individuals. When we do not have the right way to cope with, pray-for-blessings becomes a mental compensation. "Lighting the candle", "sacrificing the wine", "to burn joss sticks" and "presenting bouquets" were some traditional praying ways that have been moved to the Internet by netizens. It can be seen that folk custom is a refraction of 
primitive psychology (Xia, 2002).

In the category of "pray for China", "the Chinese are the strongest", "come on, China", "long live China", "prosperous, rich and powerful", "China is invincible", and "disaster can't knock down the Chinese" reveal the Chinese strong patriotism and the confidence in overcoming the disaster. By praying for China, people become more confident and feel safe together with the government and compatriots.

To our surprise, the category of "pray for the rescuers" only accounts for $2 \%$ of the "pray-for-blessings" elements. Seemingly, the netizens lose sight of them, however, it shows that the Chinese would like to believe in rescuers and be confident with them. Comparing with the victims in the earthquake, they appear as altruists which attract more hope than blessing from the compatriots.

\subsection{The Positive attitude of Chinese people, such as unity, great love, active cooperation}

Contemporary Chinese social mentality is also reflected by the Non pray-for-blessings elements. In the category of "cohesion", words like "unity" and "unity is strength" express the Chinese feeling of power. "Solidarity as one" and "all the people of one mind" show the sense of identity. "Family" and "powerful backing" reflect the netizens' sense of belonging. The national cohesion generates from the genetic connection, which makes our family attachment and belonging point to our nation. National cohesion comes from national identity, which generates from political relations (Huang, Huang, 2000).

Suggestions netizens gave reflect their awareness of the role as a master: "donating is better than holding a ceremony" and "wealthy people, especially the stars in entertainment field and sports field should contribute more" reflect that in front of saving lives, all the values are pointed to economic and social values, all the needs and beliefs are action-oriented. Meanwhile, "to punish the corrupt officials", "to start disaster prevention education", "to stop entertainments" and "to strengthen the structure of public buildings" are suggestions made by the netizens, which means that the Chinese people actively seek cooperation and participation in public management.

\subsection{Most of comments are positive and the social environment influence is profound}

The behaviors of netizens are towards emotion-orientation via the comments in the pray-for-blessings website. However, whether they are positive and stable is very important to the balance of organisms and the quality of life (Guo \& Wang, 2007). The individual's self-consciousness and social responsibility are being improved when they confront with the disaster. Therefore, they participate in the earthquake relief work positively or give counsel. Positive emotion can activate general action tendencies and has priming effect and extending effect on cognition. It can construct individual's resources and withdraw the activation produced by negative emotion. At the same time it can promote your physical and mental health which paves the way for a harmonious society (Liu \& Hu etc, 2008).

In the transform period of society, the rhythm of people's life is faster and faster, the competition is fiercer and fiercer, the requirement of the material life is higher and higher and the psychological pressure is greater and greater, so it has had some subtle negative emotion. In Non pray-for-blessings elements, there are pieces of negative items. "the China Seismological Bureau does not have any achievement" and "the China Seismological Bureau is useless" are posted. We expect earthquake forecast more, a great many doubts about the capability of the bureau exist after the earthquake. Furthermore, "the number of death is little", "it is fate" and "it is retribution" are also posted. Probably, individual's self-consciousness is decreasing and selfish desire is inflating in front of disaster, then they vent their dissatisfaction of the society through the Internet. Otherwise, people who suffer setbacks at ordinary times attack now (Nibler \& Harris, 2003).

\subsection{Both antitheism and theism exist}

Pray-for-blessings contain cultural origins and the figures are all deities in ancient times, so theism influences contemporary style. There is evidence from the religious beliefs, such as "Sympathizing with the victims, God, please help them". Also, the sense of family cultivated by the ancestors plays an important role, such as "the ancestors will bless you, because they are our brothers and sisters". At last, the way of thinking - "Better to Believe the worst, and be pleasantly surprised, than to be optimistic and learn the worst", such as "I didn't believe in the God, but this time, I will pray for the victims" (Pei, 2002). However, in Chinese society, antitheism constitute a large part, especially via Internet which is sense limited. Indeed, all Chinese do is making scientific knowledge on earthquake available, establishing a scientific belief and eradicating superstitions.

\section{References}

Fang, J. Y., \& Zhang, J. (2007). Mass media psychology. Hangzhou, ZJ: Zhejiang University Press.

Fredrickson, B. L. (2001). The role of positive emotions in positive psychology: The Broaden-and-Build Theory of positive emotions. American Psychologist, 56, 218-226.

Guo, X. Y., \& Wang, Z. H. (2007). Concept, function and meaning of positive emotion. Advances in Psychological 
Science, 15 (5), 810-815.

Huang, X. T. (2007). Chinanized psychology research and the construction of harmonious society. Advances in Psychological Science, 15(2), 193-195.

Jing, H. B. (2002). Three approaches to mental health in traditional Chinese culture. Acta Psychologica Sinica, 34 (3), 329-332.

Liu, H. Y., \& Hu, Z. G.. (2007). The relationship of positive and negative emotion: theories and researches, Advances in Psychological Science, 16(2), 295-301.

Nibler, R., \& Harris, K. L. (2003). The effects of culture and cohesiveness on intra group conflict and effectiveness. The Journal of Social Psychology, 143(5), 613-631.

Pei, H. Y. (2002). Chinese traditional culture's influence on modern folkloric psychology. Journal of Xi'an United University, 5(3), 24-26.

Sun, Y. Z. (2000). Meager opinion on folk words. Folklore Studies, (3), 118.

Wilber, K. (1989). Two humanistic psychologies. Journal of Humanistic Psychology, 29(2), 230-243.

Xia, W. B. (2002). A probe into Laji in ancient China in light of folk custom. Journal of Northeast Normal University (Philosophy and Social Sciences), (2), 86-88.

Yang, Y. Y. (2006). The psychological link between the individual and society: The concept of social mentality. Sociological Research, (4), 117-128.

Zhang, R. Y., \& Zuo, B. (2006). Social identity theory and it's development. Advances in Psychological Science, 14(3), 477-480.

Zou, W. W. (2006). Seismo-social psychology and propaganda on earthquake preparedness and disaster reduction. Journal of catastrophology, 21(3), 115-118.

\section{Acknowledgements}

The research described in this paper was partly supported by China Postdoctoral Science Foundation funded project (20070410478).

Table 1. Frequency of time

\begin{tabular}{ccccc}
\hline & $\begin{array}{c}72 \text { hours after the } \\
\text { earthquake }\end{array}$ & $\begin{array}{c}\text { the fourth day to } \\
\text { "Tou Qi" }\end{array}$ & $\begin{array}{c}\text { National } \\
\text { Mourning Day }\end{array}$ & total \\
\hline early morning & 30 & 23 & 55 & 108 \\
morning & 51 & 38 & 42 & 131 \\
afternoon & 49 & 26 & 91 & 166 \\
evening & 61 & 30 & 94 & 185 \\
total & 191 & 117 & 282 & 590 \\
\hline
\end{tabular}

Table 2. Frequency of positive and negative items

\begin{tabular}{cccc}
\hline & Pray-for blessings & Non pray-for-blessings & total \\
positive emotion & 709 & 199 & 908 \\
negative emotion & 5 & 154 & 159 \\
uncertain & 13 & 12 & 25 \\
total & 727 & 365 & 1092 \\
\hline
\end{tabular}

Table 3. Frequency of theism and antitheism items

\begin{tabular}{cccc}
\hline & Pray-for blessings & Non pray-for-blessings & total \\
\hline theism & 140 & 9 & 149 \\
antitheism & 571 & 348 & 919 \\
uncertain & 16 & 8 & 24 \\
total & 727 & 365 & 1092 \\
\hline
\end{tabular}




\section{Notes}

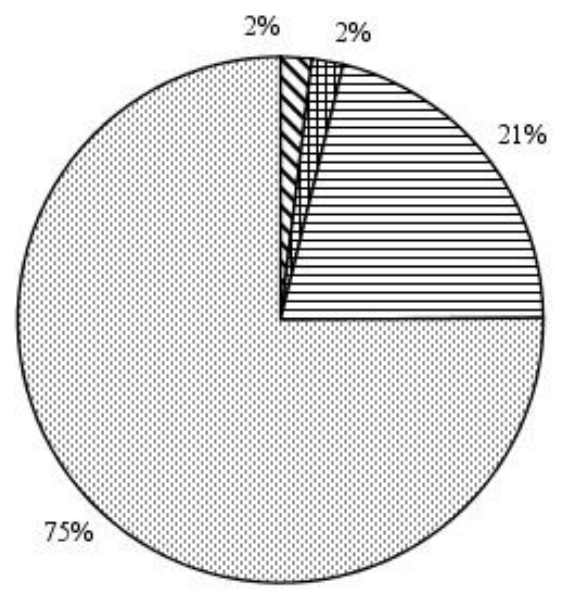

$\Delta$ pray for others

田 pray for rescuers

目 pray for China

pray for disaster areas

Figure 1. Categories of Pray-for-blessings elements

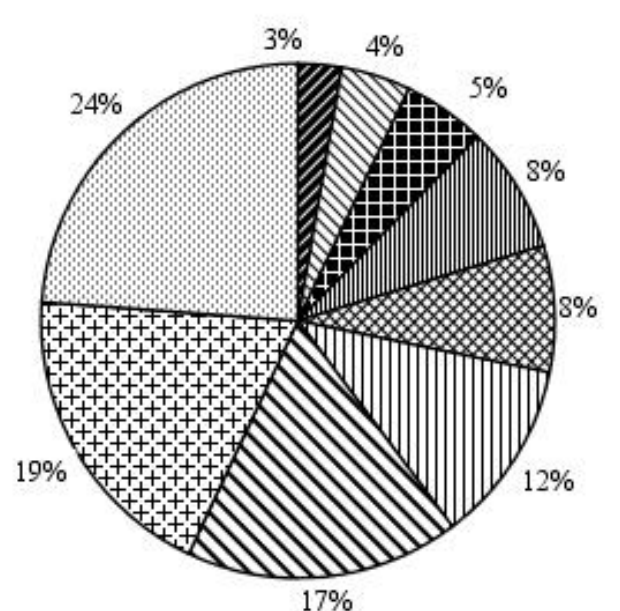

7 useless of praying

$\nabla$ schadenfreude

$\square$ information of earthquake

questioning to the China

Seismological Bureau

appreciation

四 sympathy

ه love

四 suggestions

문 group cohesion

Figure 2. Categories of Non pray-for-blessings elements 